\title{
Dossier on Govan Young: Exploring children's historical consciousness through film and archaeology
}

\author{
David Archibald (ed.)*, Stephen T. Driscoll, Catherine Doherty and Mia Perry - \\ University of Glasgow, UK
}

\begin{abstract}
Govan Young (2017) is a 30-minute documentary in which schoolchildren from Glasgow learn of the area's important but largely unknown medieval history. This dossier brings together four essays that reflect on the film from various academic perspectives - film studies, archaeology and education - to explore how schoolchildren might learn about the past, and develop a historical consciousness, by participating in film-making projects. The dossier also reflects on how educators can learn from those whom they are supposedly teaching, thereby highlighting that experimental pedagogical projects often bring unexpected learning outcomes into being. Consequently, educators must resist the pressures to predict the outcomes of projects, and must strive to keep the future open-ended.
\end{abstract}

Keywords: film; archaeology; history; place; education

\section{Introduction}

David Archibald (David.Archibald@glasgow.ac.uk)

How might knowledge of local history influence children's understanding of the place where they live? Might this new historical knowledge shape who they think they are? In what ways might film be utilized in developing this knowledge? And how might educational endeavours involving film shape children's understanding of the medium itself?

These questions emerged in the making of Govan Young (2017), a 30-minute documentary directed by David Archibald, Martin Clark and Cara Connolly, in which schoolchildren from Pirie Park Primary School in Govan, a district in south-west Glasgow, learn of the area's important but largely unknown medieval history. The full film is available at https://vimeo.com/294109808 and with English-language captions at https://vimeo.com/294137132. The film brought University of Glasgow academics working in film studies and archaeology into contact with local schoolchildren in an attempt to create an audiovisual learning experience that was both instructive and pleasurable for the participants in the film, and for those who might watch it.

This dossier contains four essays that reflect on Govan Young from various perspectives. The first two essays are written by academics who had an awareness of Govan's history and who were directly involved in the film-making process. Education scholars who had no prior knowledge of Govan's medieval importance or of the film's production context have contributed two further essays. 
The film's origins lie in a chance encounter with the writings of W.G. Sebald at a film festival in Malta. In the first essay, I detail this encounter, how it subsequently led to my own discovery of Govan's medieval past, and how this knowledge inspired the film. I then lay out some further contextualizing information, discuss the film's formal qualities and content, and sketch out the film's exhibition on the international film festival circuit. I also reflect on the central questions raised at the start of this introduction.

The second essay is by Stephen Driscoll, the archaeology professor who features in, and whose research underpins, the film. Driscoll provides more detailed historical background than features in the film itself, but also notes that the film does not simply recount historical information; rather, it operates to develop historical consciousness in the children. This is evidently a historical consciousness with a focus on the particularities of Govan's past; however, as the film illustrates, its impact goes beyond these geographical and temporal boundaries. Driscoll concludes that Govan Young could well be a model for developing learning in the community and for increasing access to higher education in working-class areas such as Govan.

Catherine Doherty offers an engaging first-hand experience of the film's UK premiere at a community screening in Govan. In highlighting the film's capacity as a time machine to transport the children from the 'here and now' to the 'here and then', Doherty notes the film's transformative impact on the children's consciousness of themselves, and of where they live, but also on her own understanding of the area. In the final essay, Mia Perry develops further the importance of place in the film. Perry also draws on the importance of the materiality of teaching, something that archaeology and film education share, and highlights that learning is never simply the conveying of knowledge but is always multidirectional. In the making of the film, our aim was certainly to teach the children, but, through the process, we learnt a lot from them - about how they view their world, their place, their histories, and about their understanding of the medium of film.

It is a commonplace in the academy that experimental modes of production that highlight cinema's constructed nature are best equipped to engender a sense of historical consciousness in the spectator. Govan Young comprises various formal qualities that draw attention to its constructedness; thus, although this project did not put cameras directly in children's hands, the participants' proximity to, and engagement with, the apparatus might well work to develop their understanding of how films actually come into being.

This dossier, then, is a small contribution to a broader discussion about utilizing film for learning about the past, and for learning about film, in schools, universities and beyond. Perhaps, however, there will always be something immeasurable and impossible to predict about the process. As I indicate in the opening essay, the origins of Govan Young lie in a chance encounter with a book containing no direct relationship with the film's subject matter, highlighting that the impact of any creative output is unknowable in advance. In this neo-liberal age of instrumentalist education, where everything is measured and quantified, it is increasingly incumbent on educators, as it is on those working in the arts, to resist the institutional pressures to predict the outcomes of experimental pedagogical engagements. For if they are to be truly successful, perhaps they will have to reach beyond the parameters of the project's own research questions or projected outcomes, and into realms that have not yet been imagined. 


\section{Places and pasts: History, archaeology, film}

\section{David Archibald}

It is July 2011, and I am at the Kinemastik Short Film Festival in Valletta, Malta, screening The Mathematics of a Dream (Abridged), a no-budget, experimental engagement with Chapter IX of The Iron Heel, Jack London's 1908 novel forewarning of a fascist dictatorship in the United States. The film was shot in a shoe-repair stall in Glasgow's Savoy Centre, but Glaswegian cobblers and American jackboots seem a world removed from the Mediterranean tranquillity of some downtime at a Maltese film festival. At my digs, a copy of W.G. Sebald's 1995 novel, The Rings of Saturn, lies discarded on a poolside table. I dive in, to Sebald, and I am captivated, mesmerized as the narrator takes me on a psychogeographical drift, in, through and between, places, times and ideas. Although far from home, for reasons indiscernible The Rings of Saturn sears on my consciousness a desire to learn something of those who had traversed the ground where I lived in times gone by.

I lived in Govan in Scotland, and had done for the best part of three decades. Govan is famous for shipbuilding. Or it used to be. Seawards the Great Ships (1961), a cinematic monument to Clydeside's world-leading shipbuilding role, won the Academy Award for Short Film and helped put Govan on the map. Govan, though, is also famous for protest, such as the women-led rent strikes, depicted in Red Skirts on Clydeside (1984), and the Upper Clyde Shipbuilders' occupation, or work-in, depicted in Cinema Action's UCS 1 (1971) and Class Struggle: Film from the Clyde (1977). The most recognizable audiovisual depictions of Govan in recent years, however, are less celebratory, emerging in Rab C. Nesbitt (BBC, 1988-99 and 2008-14), a bleak, if comic, televisual mapping of Govan's post-industrial decline.

In 2011, I knew fragments of Govan's pre-shipbuilding history; it was a centre for weaving in the nineteenth century, and Govan Old Church housed an important collection of ancient stones. Like the overwhelming majority of Govanites, however, details were sketchy at best. On an enthusiastic hunt to partially fill this historical lacuna, I scoured the internet and discovered a link to The History of Govan (Dalglish and Driscoll, 2009). I am somewhat embarrassed to say that as I leafed through a copy in the University of Glasgow library, I was reading for the first time of a Viking siege at Dumbarton Rock, a few miles down the Clyde estuary, in AD 870, and the subsequent establishment of a Brittonic kingdom that ruled much of Clydeside from 900 to 1100 . I was astonished when I read that this new kingdom, the Kingdom of Strathclyde, had its spiritual centre in Govan.

Equipped with scraps of newly acquired historical knowledge, I set about evangelizing for medieval Govan, and secured seed funding from the University of Glasgow's Chancellor's Fund, and further small grants from Historic Scotland and the Heritage Lottery Fund. The funding was secured for the stated aims of improving awareness of Govan's history, locally and internationally, enhancing the cultural heritage of Glasgow and Scotland, and exploring how to depict Govan's medieval past in film. Robert A. Rosenstone (1995: 63) suggests that the task of experimental historical cinema is 'to open a window onto a different way of thinking about the past'. I wanted to open a window onto a different way of thinking about Govan's past, but also onto a different way of thinking about how we might learn about Govan's past with and through film. Working with a local production company, Connolly Clark Films, we explored various ways of recounting this history in a manner that would resist the mundanities of mainstream television history, yet produce something that people in Govan could find relatable, aiming to experiment formally yet connect locally. We settled on the idea of 
recounting the history or, perhaps more accurately, a consciousness of that history, with the aid of local schoolchildren and various local community groups. The advantage here was that we could recount the history directly to the children, and they could learn, while simultaneously, and seemingly inadvertently, the film's audience could also learn, yet feel free from the perceived strictures of pedagogical instruction.

The result is Govan Young, a 30-minute documentary that follows a group of Primary 4 children, aged 7 and 8, from Govan's Pirie Park Primary School as, aided by Stephen Driscoll, Professor of Historical Archaeology at the University of Glasgow (who provides the second essay in this dossier), they learn that one thousand years ago, Vikings and kings walked on the ground beneath their feet. The film is divided into six segments: (1) a day trip from Dumbarton Rock to Govan on a small sailboat with a handful of schoolchildren, a teacher and Driscoll; (2) introductory interviews with schoolchildren on their thoughts about Govan and its history; (3) a lesson delivered by Driscoll to the pupils, which also utilizes footage of short films containing historical re-enactments of imagined rituals from medieval Govan, acted out by children from a National Theatre of Scotland workshop; (4) a field trip with approximately sixty children to Doomster Hill, the River Clyde and Govan Old Church, during which the party is ambushed by sword- and spear-wielding warriors dressed in Highland attire from the community organization, GalGael; (5) a concluding set of interviews in which the children reflect on what they have learnt; and (6) closing credits over which the children speculate gruesomely on how best they might dispatch a king without spilling royal blood. In addition, a voice-over from Govan's own lain Robertson, a familiar face in film and television in Scotland, most recently in the soap opera River City (BBC, 2002present), peppers the multilayered film with historical detail.

Govan Young does not set out to teach young people about film, or at least it does not address these matters directly. In a different project, one with greater time and resources, the children could have been tasked with direct involvement in the filmmaking process - scripting the narration, storyboarding, filming the action, or even being supported to make their own individual or group films. There are many instances of more directly participatory projects, such as the work of Paul Cooke and the Arts and Humanities Research Council-funded project Changing the Story on participatory film-making with young people in post-conflict zones (https://ahrc.ukri.org/research/ readwatchlisten/features/changing-the-story/), but in Govan Young the children are involved in the process as active agents in front of the camera rather than behind it.

As we see in the film, in the initial interviews the children hold mixed views about where they live. While one or two are positive, many are negative, citing litter, dogs' excrement, and alcoholism as problems besmirching the local community. Unsurprisingly, they know little of Govan's past. The history they do recount is one unperturbed by fidelity to the historical record. In their medieval Govan, fact, fiction and fantasy merge: people wear silk trousers, live in tents and walk cats on leads; the Disney character Scrooge McDuck runs the shipyards like the worst Dickensian capitalist, and the past is not a place they would like to have lived in, because it is 'in black and white'. As the children encounter a new history, from Driscoll, from the drama workshop films, from the GalGael re-enactors, the past becomes colourized, perhaps tangible. There is a touching moment as one of the boys enthuses to his teacher that when he returns home he plans to visit Viking websites and record what he has learnt. As he skips down the church stairs and into the graveyard, he says, buoyantly, 'this has been the best day of my life'.

One of the things I learnt in making the film was that many of the children viewed where they lived as a place of no importance. In the first set of interviews, for instance, 
one of the boys is asked if Govan is important and he responds, 'Nah, not really.' He pauses, before shaking his head and adding, 'Not at all.' It is a bleak answer. Yet, responding to a similar question in the concluding interviews, after the lesson and field trip, he proceeds to state that Govan is indeed important, before recounting all that he has learnt, of the kings of Strathclyde, of the river and of the Vikings. It is a small example of the transformative influence that imparting knowledge of local history can have on how children view their own small world. If it had only influenced these children, for me, it would have been worth all the grant money and more; however, the cinematic record of their experience has ensured that it has reached beyond the perimeter of the school. For example, the National Library of Scotland Moving Image Archive and Glasgow Museums are also using Govan Young on a joint career-long professional development programme on the topic of using e-resources to explore local history in the classroom

At a screening for academics in December 2016, I indicated that we hoped to circulate Govan Young on the international film festival circuit, but that I was uncertain of the response it would receive. One attendee indicated that the film, as he saw it, was about children in search of a lost kingdom, and speculated that it might have some appeal. Such has been the case, and the film has now screened at over twenty film festivals across four continents. The film had its world premiere at the Ninth Lucknow International Children's Film Festival in India in May 2017, which organizers claim is the world's largest children's film festival. Here, three thousand local children crammed into a vast auditorium adorned with banners carrying slogans advocating the ethos of the school, one of 'meaningful' education. The festival is quite explicit that they are utilizing film as an educational tool to shape the attendees' world-views; as Festival Director, Varghese Kurian, writes in the festival brochure, 'The objective of the entire exercise ... is to provide a gateway to exploring complex ideas and open children's eyes to other ways of looking at the world' (Ninth Lucknow International Children's Film Festival Brochure, 2017: iv). He adds that the festival has an underlying message of 'Jai Jagat (Hail the World)', and laments that important values are being lost in what he describes as 'rather meaningless mainstream cinema' (ibid.). Over the course of the festival, the children are bussed in and out daily and greeted on every arrival by a small military band as they are marched up the red carpet to watch a host of education-related films, many of them set in schools or involving schoolchildren from many different parts of the world. While watching children from India engage with a film about medieval Govan, a film that had its origins at a festival in Malta, it was impossible not to think about the way creative projects invariably drift, in a Debordian sense, beyond the expectations of their creators (Debord, 1997).

Govan Young may have traversed the world, but its importance and its strength lie closer to home. Govan was the heart and soul of this film in every sense: the children, the narrator, GalGael, the school and its staff, the church, the Govan Stones, Doomster Hill. Although she does not feature in the film, the school's head teacher, Jane Arthur, deserves a gold star for engaging so enthusiastically with the project and agreeing to all the requests for support and assistance in filming. When hundreds of local people assembled in Govan Old Church for the UK premiere in September 2017, many no doubt encountering both the history and the stones for the first time, there was a palpable sense of a community coming together in a manner that we are told is increasingly rare. The sense of community finds a parallel in the film's penultimate scene: as the children march buoyantly home from their field trip, their Viking shields intact, their voices in good timbre, contemplating the complex histories buried below, they chant in unison 'We're from Govan, we're from Govan.' It is a living, breathing 
illustration of geographer Doreen Massey's (1994) theories on how a sense of place might influence identity in a progressive manner.

Who knows what the long-term impact on the fifty or sixty children involved in the process will be? In many ways it can only be immeasurable and impossible to predict. As seems evident in the finished film, the children had an enjoyable, if indirect, film education experience, from participating in drama workshops, observing a film crew in their classroom and on field trips, participating in filmed interviews, and attending the cast and crew screening and then the red-carpet premiere in Govan Old. Will some of the children drift into the world of film and television after their own chance encounter with the medium? Certainly, if one or two ended up behind or in front of a film or television camera in years to come, it would not surprise me. What seems more certain is that through the making of the film, the children's own understanding, not only of what Govan is, but also of where they are, and who they are, has been made complex, shifting from the singular to the multiple, through this pedagogical engagement with local history, combining archaeology and film.

\title{
Raising historical awareness with archaeology and film: Reflecting on Govan Young
}

\author{
Stephen T. Driscoll (stephen.driscoll@glasgow.ac.uk)
}

Historical education in Govan presents many challenges, but lack of material is not one of them. Govan has glorious rich veins of readily accessible history, which remain largely unknown because most people presume that nothing noteworthy occurred here beyond shipbuilding. Overcoming that presumption of insignificance involves looking below the current landscape, investigating unfashionable terrain, such as Victorian churches or nondescript car parks, and engaging with difficult and opaque evidence, such as pieces of thousand-year-old sculpture. In a place such as Govan, the purpose of historical education is to build cultural confidence and consciousness. Here, archaeology provides a valuable approach. It is a practical activity, involving tangible materials and, dare one say it, is non-threatening because nobody (apart from an archaeologist) is expected to know much about it. In other words, people can feel curious without their ignorance being an impediment.

Govan presents significant interpretive challenges for the archaeological educationalist, not least its obscure, church-based historical narrative: What was the kingdom of Strathclyde? Who was St Constantine? What is a hogback stone? How did Govan Old Church come to be important? These and other challenges have been examined at some length (Driscoll, 2016), but the issues remain and need to be grappled with on a case-by-case basis. Govan Young (2017) addresses those challenges by combining archaeology and film-making in a project involving local schoolchildren. In doing so, it normalizes the uncertainty of new, alien information and highlights the process of learning through instruction, enquiry and physical engagement. In recent decades, visual media and film have become increasingly significant for archaeology as a discipline, because by comparison with other historical methods, archaeology is dynamic and (potentially) photogenic, therefore making it visually attractive. Indeed, film has provided a valuable means of documenting archaeological investigations in Govan since the 1990s. Films concerned with Govan Old's ancient history began to appear as a direct consequence of the archaeological investigations by the University of Glasgow beginning in the 1990s. The excavation works also attracted the attention of the producers of the popular Time Team television series (Channel 4, 1994-2014), who saw an episode set in the heart of gritty urban Glasgow as providing a nice contrast to 
their usual English bucolic fare. In 1996, Time Team visited the area to discover traces of the lost Celtic kingdom of Strathclyde. A shorter, more scholarly television reading of the Govan Stones was presented by Michael Wood in his Great British Story: A people's history (BBC, 2012). However, until Govan Young, film had not been explicitly utilized for educational ends.

The involvement of children in an archaeological project is also not unusual; educational outreach is commonplace in contemporary archaeology practice. What sets Govan Young apart, though, and what emerges clearly in viewing the completed film, is the degree to which the interests and responses of the child participants are foregrounded and taken seriously, as evidenced by the extensive interviews with the children that frame the film.

Govan Old has one of the longest histories of any church in Scotland. Archaeological investigations have established that it began as a place of burial and worship around AD 500 (Dalglish and Driscoll, 2009: 36). The church contains a collection of early medieval sculpture, known as the 'Govan Stones' (c. AD 900-1100), which has been interpreted as evidence that Govan was the cult centre and dynastic burial ground for the kingdom of Strathclyde. Despite this historical significance, the Govan Stones remain poorly known outside scholarly circles.

Govan Young brings this ancient and unknown past into dialogue with the present through the modern medium of cinema. The children in the film are Primary 4 pupils from Pirie Park Primary, a modern non-denominational school located in central Govan, a mile or so south-west of Govan Old. The school was selected for its proximity and, like most Govan residents, it was not anticipated that the 7- and 8-year-old pupils would have much, if any, prior awareness of the history and archaeology at Govan Old Church. Contemporary archaeology is largely funded through public bodies, or by developers who are compelled by planning regulation to provide funding; consequently, good archaeological practice involves a degree of public engagement. School visits, guided tours, public lectures and temporary displays are the most common engagement methods. Film is becoming more common, but tends to take the form of descriptive reportage. Govan Young utilized these traditional engagement methods, including a short show-and-tell 'lesson' from a visiting archaeologist and a site tour, but here the focus of the film is not solely on the local archaeology, but rather on the process of developing historical consciousness through the encounter of archaeology and film. The archaeologist introduces tangible traces of the past and guides the pupils to think about how artefacts relate to the past, but it is through the process of filming interviews that the pupils can reflect on and consolidate their new knowledge. What was even more unusual in a public engagement context was that we sought out Govan people to examine why this remarkable history was virtually unknown locally, and whether that situation could be altered. The focus on children from a working-class neighbourhood is also unusual in the context of archaeology films; archaeology audiences, when self-selected, are predominantly middle class. The universality of cinema here seems to unlock a sort of knowledge that is typically confined to the middle and upper classes.

While Govan Young builds upon conventional approaches to archaeology outreach, the process of creating a film in the classroom introduces a new dimension. In our media-dominated environment, the production of a film confers value on a subject, so the very process of documenting the sessions stimulated a high level of interest and engagement on the part of the pupils. The ability to draw upon a local hero, the actor, lain Robertson, clearly enhanced the value of the project, because not only was he a familiar figure from the world of film and television, but as a Govanite he 
could connect readily with the pupils. As a method for reaching wider, socially diverse audiences, the film-making process has proved to be powerful. In many respects, Govan is an exceptional place, but it is far from unique in having a hidden history or an archaeology that could be exploited to engender a sense of local pride and, more importantly, to inspire intellectual curiosity among pupils. In short, Govan Young could well be a model for enhancing pupil engagement, encouraging learning of both archaeology and film, and, ultimately, widening access to higher education.

In making the film, our aim was not to explore the fine details of the early medieval sculpture or delve deeply into the history of the kingdom of Strathclyde. Rather, it was to examine how best to connect young Govanites with their hidden past. Of the various strategies deployed in Govan Young, the most self-consciously dramatic were the use in the classroom of filmed footage of young members of a National Theatre of Scotland drama group performing impromptu drama sketches in Govan Old churchyard and the involvement of re-enactors dressed as Highlanders. The link between the two activities was provided by Robertson, who led the drama workshops and dressed as a wild Highlander when visiting the class. The other reenactors, from the GalGael Trust, cut dashing figures with their plaids, swords, spears and shields. While perhaps not an authentic representation of Viking Age warriors, they nevertheless helped the children to conjure up images of an early medieval world, and as part of the visit to Govan Old they ensured it was a memorable experience for all. The importance of filming these encounters is that they give the lived re-enacting experience an equal footing to the static archaeological evidence, reinforcing the value of the archaeology by linking it to contemporary activities.

The practice of dressing interpreters in period costume as an educational tool has a well-developed and successful pedigree in archaeological contexts. Perhaps the most well-known example is found at Williamsburg, Virginia, where the eighteenth-century town has been rebuilt following archaeological excavations and is populated by dozens of colonial characters who act out events associated with the American Revolution (www.colonialwilliamsburg.com). An example closer in time and space to early medieval Govan is provided by the Jorvik Viking Centre in York (www.jorvikvikingcentre.co.uk). Here we also have an immersive urban reconstruction based upon meticulous archaeological excavations. At Jorvik, costumed interpreters serve as guides to the displays and demonstrators of period crafts. However, apart from their craftwork they do not role play; rather, they use costume to attract the interest of visitors and serve as interpretive resources. Although not underpinned by the sort of scholarly rigour that characterizes Williamsburg and Jorvik, the GalGael established a powerful connection with the pupils, which in this context is important because it made the experience of visiting Govan Old arresting and memorable. Arguably, authenticity is less important than stimulating interest and building historical consciousness. Far from being a peripheral element, alongside the film-makers, the GalGael re-enactors were critical to allowing the pupils to 'experience' their past.

While dramatic techniques were used to capture the children's attention, a parallel strategy was followed to provide an authentic archaeological experience. The school visit by the project archaeologist, supported by a few Indiana Jones props, established the legitimacy of the evidence, which was reinforced by a handling session with artefacts and archaeological tools. This set up the most important educational experience: the visit to see the Govan Stones. The value of the encounter with Govan Old cannot be overestimated in this context, because it seems likely that none of the pupils had ever previously visited the church despite its proximity. In its slightly secluded location, the churchyard contains monuments with spooky carvings, such as 
skull and crossbones, surprising the children, who had no expectation of encountering a site of mystery on their doorstep. Indeed, finding themselves in church seemed to be a novelty for many of the children and, certainly, being 'let loose' in church with no service or minister was clearly liberating.

The most tangible experience was provided by the Govan Stones themselves, which on the one hand have images that are intelligible, such as crosses and horse riders, but on the other hand are strange and unfamiliar. As an archaeologist, I am aware that the warrior carved into the thousand-year-old sarcophagus was less vivid than the living, breathing GalGael Trust warrior, but I also hope that the combination of the two allows a rich experience of the visit to Govan Old to be retained.

On the evidence of the film, this combination of activities is an effective way of reaching pupils and enriching their awareness of the historicity of their surroundings. It is a time-consuming, resource-intensive approach, which poses the challenge of how to deliver such an educational experience to the next Primary 4 class, and the next. The success of the film with international audiences suggests that screening the film coupled with a visit to Govan Old could have a similarly transformative effect on this year's Primary 4 class. Whether such an apparently deep transformation could be achieved without the involvement of (stimulating) outsiders is a question worth examining by using the film and sites with different school audiences and assessing its effectiveness. There is no question that, as the archaeologist seeing the transformative impact of the project, this was highly encouraging. Clearly, delivering this experience more widely brings its own challenges, but at least we know it works.

\section{Going back to Govan: Reflecting on temporal scales for knowing the 'here and then'}

\section{Catherine Doherty (catherine.doherty@glasgow.ac.uk)}

I had the pleasure of attending the community launch of Govan Young (2017) in September 2017. The event was held in Govan Old Church, which features in the film. Govan is now a suburb of Glasgow on the south bank of the River Clyde, with a layered history as the seat of the ancient Briton kingdom of Strathclyde, more recently as the site for boom and bust cycles of the shipbuilding industry, and plenty in between. I had not visited this part of Glasgow before. Moreover, as a relative newcomer to Scotland, I was ignorant of what 'Govan' entailed in any contemporary or historical sense. Emerging from the nearby subway station, I encountered the faded grandeur of old sandstone buildings overlooking takeaway shops, bus stops and pubs at street level. I was early, so I took the opportunity to wander around the quiet streets, across a car park to look at the river, through the graveyard outside the church, then among the museum artefacts on display inside.

Such mundane encounters with deep history may be commonplace for some, but they cannot be taken for granted by me as a white Australian. Growing up in colonial Australia meant an education in the scorched earth principle of terra nullius, a fiction that cultivated wilful ignorance, if not purposeful erasure, of any human histories prior to British invasion. In my schooling, the only history that mattered started when people like me arrived. By contrast, in the United Kingdom, the history of place is deep and resonant. The 'here and now' is saturated with clues and cues to the 'here and then'.

I was initially attracted to the launch by the trailer's choice moments of children talking. As an educator, that will draw me in every time. In this way, the film first presents itself as a charming assault on the senses through interviews with children from Pirie Park 
Primary, aged 7 and 8, with over-sized teeth, prominent ears and delightful accents. On one level, the film records a pedagogic sequence. The broad device of filming children in the process of learning about the deep history of where they live offers a narrative arc. We witness the children move from relative ignorance of, and detachment from, Govan's medieval history, towards pride and appreciation of their locality as a 'place of kings'. Children are interviewed before and after a series of learning events that engage them with Govan's historical encounters between Briton kings and Vikings. In these unscripted dialogues, the camera dwells on individual children, capturing every flicker of eyes, wrinkle of nose, wriggle of shoulders and creasing of forehead involved in the act of thinking. The calm pacing of these exchanges, with their generous silences and patient gaze, produces priceless responses and some real characters.

For someone involved in teacher education, these dialogues exemplify the value of 'wait time' - the time allowed for thinking between teacher question and pupil answer, time that is so often rushed or sacrificed in classroom settings. Here the silences are filled visually with a close-up of the bodily act of thinking writ large across unselfconscious faces and wriggly bodies. This capture of the act of thinking is as engrossing as their answers. At other times, the children respond quickly with a certainty of opinion about rubbish on the streets, sisters with Viking blood, or Govan being 'near Asda, KFC, Pizza Hut and McDonald's'. No pondering time is necessary on these matters; they know this 'here and now' well. These dialogues are also exemplars of extended responses by pupils to genuine questions, not the usual heuristic pseudoquestions of teachers and restricted pupil responses that drive much classroom talk. We also see pupils ask questions of their own. They are fascinated by the topic of death, quizzing the archaeologist who steers them through this engagement with the deep past.

In this way, the film is both about pedagogy and a pedagogic tool in itself. There is a rich, tactile and interactive pedagogy depicted in the film, and then there is the engaging pedagogy of the film, which works on the audience as they also build knowledge about both the 'here and now' and the 'here and then' of this place. The magic of this documentary, however, is that the audience learns from the mouths of babes.

One intriguing scene is the film-within-the-film: we watch the schoolchildren as they watch a film of children re-enacting the burial of a Briton king on the site of Govan Old Church. There are no costumes involved, just serious purpose and deep immersion in the roles to recreate the tale. The class group are riveted and, in turn, we as audience are riveted by their close attention and their thoughtful, quirky questions as they link the past to the present.

We are privy to the mounting excitement of the class excursion to the church through the park. Home-made Viking shields are brandished, spirits are high, and the Highland warriors they encounter en route do not disappoint, ensuring 'safe passage' to the church grounds. In the Old Church, the pupils meet the hogback stones and an engraved sarcophagus from the graves that they first saw in the film-within-the-film. These are priceless museum artefacts available to be touched, their looming size and textures irresistible to little hands. In the second set of interviews, which take place after the field trip, the pupils try out new words in their recounting of what they have learnt. Their hand gestures outline and stroke the stones again in their retelling - 'One is so smooth and bright! The rest are like rocky and all that!'

At the launch, the church was packed with members of the local community, who responded to the film with great warmth, pride and humour. During the postscreening discussion, one member of the audience asked, 'Why isn't schooling always 
like this?' I could have answered this question, explaining the many constraints and demands imposed on teachers and schools by testing regimes, risk-management accountabilities and limited budgets. But in contrast, the school's head teacher, Jane Arthur, talked of how their participation in this film project had indeed precipitated other enquiries and projects. Learning was going to be a lot more like this for this school community.

On reflection, the learning experiences for both participants and audience offered a mode of time travel. The children are going 'back to Govan' in time. Indeed, the opening sequence gives us a spatial sense of 'going back' as a small boat passes Dumbarton Rock, with its ancient fortress, social housing towers and Clydeside factories. However, the voice-over constructs a temporal sense of going back in time, with references to the area's central role in shipbuilding and social protest. The children demonstrate some familiarity with Clydeside's history of shipbuilding through the experiences of their family members. This history is well-rehearsed in the public imaginary, where the history of greater Glasgow seems to have stalled at the No Mean City (McArthur and Kingsley Long, 1957) moment of widespread unemployment, slum tenements and ingrained poverty. The 1941 bombing of Clydeside is still living history, and continues to be a sore point in the Glaswegian community. While these narratives of the recent past occupy centre stage in the social imaginary, deeper histories are obscured, although their traces remain right under the community's nose. Like the two ends of a telescope, it seems hard to maintain both temporal scales in focus.

The concept of scale refers to the 'ordering of sociospatial units within multiple hierarchies of power' (Çağlar and Glick Schiller, 2011: 6). In social science, there has been renewed interest in the geographic concept of 'scale' and its metaphoric use to account for the 'upscaling' or 'scale jumping' of sociality under processes of globalization, transnationalism and regionalization (Canagarajah and De Costa, 2016). Scaling practices are now understood as active processes that constitute, organize and regulate space. In this way, people create and impose scales, and these scalar categories come to matter. I would like to divert this discussion to consider temporal scale, and how we equally set and regulate our temporal parameters.

Like the rest of us, these children live in the here and now, experts in what their locality means to them: 'It's an important place to people who live in Govan because that's where our houses are, really.' The learning experiences captured in the film invite them (and the audience) to radically shift the temporal scale from 'here and now' to 'here and then'. To the film-makers' credit, this time travel is achieved without a Tardis or ponderous documentary realism. We jump scale to plummet down the centuries through the children's imagination, to re-story Govan as more than 'just a place': it becomes a place with a deep, intriguing story. The trope of 'Viking blood' emerges at times to express a sense of intergenerational continuity and connection across centuries: 'They came and stayed!' The children of Asian and African appearance are as excited by this as their counterparts - they've come and stayed too, just like the Vikings, and will be similarly folded into history over time.

As I left the launch, I retraced my steps through the churchyard and the car park, but this time, I was less ignorant, thanks to the pedagogic work of the film. Rather, I was conscious that I was walking over venerable burial sites and the remains of Doomster Hill. I was walking on deep history, in the 'here and then', and will never look at Govan in the same way. 


\title{
Versions of place and status of stories: Govan Young
}

\author{
Mia Perry (mia.perry@glasgow.ac.uk)
}

Encountering this short film as an educational researcher came as a break, or a breath in the day. Whether watching at work, in an office or classroom, or at home in a sitting room, this short film is an invitation to pause (briefly), to listen and watch, and await what might be on offer: Will I learn something new? Will I be distracted from my dayto-day trials and tribulations? Will I be inspired or amused? I came to watch Govan Young (2017) by invitation from a colleague who connected the film's themes with my own work in educational scholarship. I was intrigued, and welcomed the opportunity to engage with a new lens on place, education and youth in Glasgow.

I am a teacher, a teacher-educator and a researcher practising in the intersections of contemporary arts, literacies and education. I am interested in the relationships and differences (human and non-human; spatial and material) inherent in every learning engagement. And I am interested in the ways in which cultural products, such as film, can mediate and support teaching and learning. My reflections and responses to Govan Young come from these perspectives, and I share them as a series of notes relating to pivotal characteristics or tools of teaching and learning. I lean heavily on an awareness of place and materiality in learning, that is, the role that things and 'stuff' have in learning engagements: places, costumes, landscapes, boats, cardboard and so on (see, for example, Coole and Frost 2013; Ellsworth and Kruse, 2013; Kuby et al., 2015; Sommerville, 2007). I also focus on the cultural, performative and creative aspects present in teaching and learning, and look for spaces where an explicit awareness of this can benefit or shift educational practices (Ellsworth, 2005; Perry and Medina, 2011).

\section{Place}

Place is at the centre of Govan Young; it is in the title, it is the location, it directs the narrative commentary, and it focuses the questions asked in the interviews with the schoolchildren that bookend the film. Through explicit narration describing Govan, accompanied by a visual journey through related aspects of the place, the area is introduced as a specific, historically, socially and politically complex location. It is the commitment to place, and what it offers in terms of plot, social comment and community cohesion, that gives this film its weight and points to its educational impact. I wonder how powerful a curriculum and a teaching practice might be, if place was equally at the centre. If, as with Govan Young, place can offer inherent plot (all places have stories to tell), if place can prompt social commentary (all places inform, if not determine, the social responses therein), if place can promote community cohesion (through appealing to those who feel belonging, or providing a sense of belonging to those who do not), then place may be as central to schooling as the lesson plans, peers and walls that currently characterize schooling.

\section{Perspective}

In the opening scene of Govan Young, we see a group of children on a small boat as it moves slowly along the Firth of Clyde. 'Where are we going?' asks one of the occupants; 'Back to Govan!' comes the reply. As we watch, we, and the children, see Govan from the point of view of this small inlet off the Atlantic Ocean, from a boat. We see it from an angle, and in a perspective, that we have not done before - from a distance, but also in relation to coastline, to ocean and to an expanse of sky. I imagine what that dramatic difference of perspective does for a child who lives in Govan. I compare it with how 
it feels when I see my home village from the window of a plane flying overhead. The place suddenly appears to exist as a little part of a bigger and much less familiar whole. In Govan Young, the perspective of space is only a taster for the much more profound perspective across time that the film proceeds to generate as it rewinds a millennium or so. A place in the perspective of time gone by is a place transformed in the eyes of many young people, as portrayed in this film. Their perspectives are dominated by the present, coloured by diverse and speckled ideas of a past in 'black and white', or one where people wore 'silk trousers' and 'wooden shoes'. This type of perspective transcends the history curriculum but has an impact on all aspects of learning and living in a place. The old adage stands true: it is hard to see where you are going if you do not know where you have come from. And yet, in addition to this, every place, person, thing or interaction has multiple sides, dimensions or facets. What I see as one thing, my neighbour sees as something else, in part because she is looking at it from a slightly different angle.

\section{Stories}

Whether weighted with fact or fancy, we make sense of place and self through story. Govan Young is a feast of stories, fact and fiction rubbing up against one another, teasing and testing, vying for primacy. The children's voices interweave to create a compelling story of innocence and naivety, but also of truths and sincerity. Their stories paint a picture of Govan recognizable by its grocery stores and fast-food restaurants, dogs and litter. Govan is important 'because it's where our houses are'; where 'famous people like Alex Ferguson is from'; there are 'loads of trees' and 'a lot of dogs' dirt'. Their histories are speckled with myth, shipbuilding history, popular culture and a good deal of uncertainty. Govan was a place 'where cats used to be walked instead of dogs'; where the biggest ship was built; where the 'children worked for McScrooge [sic], who was old and selfish'; where it was 'black and white'. These stories mediate these children's relationship with their home - and there is a beauty to that, a relevance and specificity to that - stories that emerge from their own tangible engagement and experience with life in Govan (life that includes fact and fiction, interpretation and speculation). But these stories are put in relation to very different voices - voices of historians, experts of a different type.

These voices are those of adults, but they are not simply voices of validation, attempting to embody, interpret or illustrate the stories of the children. They were there to bring a very different story to the experience of Govan. These voices were guests from the university, the people from outside Govan (the interviewer, the archaeologist). They were supported by the ubiquitous story of the faceless narrator with a gentle Scottish accent that oozed 'belonging' to his historical story (lain Robertson, himself from Govan), and brought with it an authority and validity in this context that is unique in the film.

Of course, each of the stories (those of the children, those of the historians and even that of the narrator) is based on a set of values and perspectives that 'land' over the course of the film, and together contribute to a political as well as an aesthetic overview and tone. Some examples of what comes across include a national pride, a valuing of power and wealth, a grand past in relation to a bleak present. 'Kings of past', 'the political centre' and a 'spiritual heart' were layers of Govan's past shared and shown to the children that contrasted with the children's perceptions of the 'dark houses' of today, the litter and 'just people like us'. The children visited the historical Govan Stones in Govan Old Church; one child's first response was, 'Hogwarts, seriously!' As a viewer, moving and being moved by the narratives interwoven in this film, I am 
struck by the multiplicities of experience: the difference between a glorious past and a perceived present is a highly relative and interdependent equation.

I wonder why the stories seem to settle into places of relative priority or 'truthiness' - the children's stories perhaps revealing only their naivety, but the adults' histories presented as truth. I wonder about the power that story has to influence, and to determine, the experience of a place. And if it is powerful in this role, who gets to tell the story? And with whose knowledge? These questions were beautifully, and not neutrally, entertained in Govan Young, and cut right to the heart of the business of knowledge in our education systems. In Govan Young, the interviewer asks the children questions about Govan, and acknowledges the answers through listening and recording them. The children ask the archaeologist questions in the classroom and validate the answers through listening and incorporating them into their own imaginaries. In education, as the children's knowledge and understanding of place is put in relation to the adults' knowledge and understanding, the outcome typically in classrooms is a 'correct' and 'incorrect' version (the correct version being that of the adult expert). The experience of viewing Govan Young reminds us that teaching and learning could be an emerging collective understanding of place, past and future that includes multiple perspectives and experiences.

\section{Experts}

Who is really the expert then? Who really does the teaching in a pedagogy of place, history and future? Is it the materiality of this place itself? (If you don't know the history, is it really there?) Based on the playfulness, based on the purpose, and on the prioritizing of stories in the Govan Young project, my bet is that the people who wield that influence on the children in this film are those very men who apparently wielded influence a thousand years ago - the tall, cloaked, red-bearded, rugged tribesmen who ambush the children as they move through Elder Park before securing their safe passage on the remainder of their journey. The men, members of a local community trust, GalGael, enact historical events, characters and activities today, and in Govan Young they playfully but authoritatively direct the children, as they speak of warfare, culture and conduct. Unlike the historians and the children, the tribesmen-in-role not only spoke of the 'truths' of times gone by, but they spoke like those imagined times gone by. They looked like them, felt like them and perhaps, if even momentarily, they made you feel what it might have felt to encounter them. As I look back on my own experience of Govan through the film Govan Young, I think of the GalGael group, of how the characters compelled me and entertained me, but also reminded me very quickly of the less romantic and exciting side of history. The timelessness of winners and losers, war and death, power, and gender. How history, embodied and made material, feeds vibrantly into a present and a future - a history that otherwise weighs in my imagination like Scrooge McDuck, Hogwarts and silk trousers.

\section{Notes on the contributors}

David Archibald is Senior Lecturer in Film and Television Studies at the University of Glasgow. His academic work includes the monograph The War That Won't Die: The Spanish Civil War in cinema (2012) and he has published widely on various aspects of film culture. David has worked on numerous films, most recently a film about Guy Debord, written and directed with Carl Lavery. He regularly appears on stage alongside Lavery in Glasgow Glam Rock Dialogues. 
Catherine Doherty is Professor of Pedagogy and Social Justice in the School of Education at the University of Glasgow. She works in the fields of sociology of education and applied linguistics. Her research has explored transnational curriculum, mobile populations, classroom discourse, pedagogic morality and educational policy in both higher education and schooling settings.

Professor Stephen Driscoll specialises in the archaeology of medieval Scotland with an emphasis on the Early Middle Ages. He has conducted large-scale excavations at Edinburgh Castle, Glasgow Cathedral and the Pictish royal site at Forteviot, Perthshire. His archaeological investigations in Govan were prompted by its early medieval significance, but over the years this interest has expanded to utilize Govan's cultural heritage assets to promote social and economic improvement. He is a member of the Govan Heritage Trust, which owns Govan Old Church.

Mia Perry is a senior lecturer in the School of Education at the University of Glasgow. She teaches in social arts and community and adult education, and her research focuses on contemporary cultural and arts practices in relation to formal and informal literacy education. She is interested in the learning opportunities of making and witnessing arts and culture, the relationships (human and non-human) inherent in every learning engagement, and perspectives on those engagements that account for more than representable signifiers.

\section{Filmography}

Class Struggle: Film from the Clyde (GB 1977, Cinema Action)

Govan Young (GB 2017, David Archibald, Martin Clark and Cara Connolly)

The Great British Story: A people's history (GB 2012, Nick Green, BBC)

Rab C. Nesbitt (GB 1988-99 and 2008-14, Colin Gilbert, Brian Jobson, Ron Bain, BBC)

Red Skirts on Clydeside (GB 1984, Jenny Woodley and Christine Bellamy)

River City (GB 2002-present, various, BBC)

Seawards the Great Ships (GB 1961, Hilary Harris)

Time Team (GB 1994-2014, various, Channel 4)

UCS 1 (GB 1971, Cinema Action)

\section{References}

Çağlar, A. and Glick Schiller, N. (2011) 'Introduction: Migrants and cities'. In Glick Schiller, N. and Çağlar, A. (eds) Locating Migration: Rescaling cities and migrants. Ithaca, NY: Cornell University Press, 1-22.

Canagarajah, S. and De Costa, P.I. (2016) 'Introduction: Scales analysis, and its uses and prospects in educational linguistics'. Linguistics and Education, 34, 1-10.

Coole, D. and Frost, S. (eds) (2013) New Materialisms: Ontology, agency, and politics. Durham, NC: Duke University Press.

Dalglish, C. and Driscoll, S.T. (2009) Historic Govan: Archaeology and development. York: Council for British Archaeology.

Debord, G. (1997) Theory of the Dérive. London: Atlantic Books.

Driscoll, S.T. (2016) 'Reading Govan Old: Interpretative challenges and aspirations'. In Hunter, F. and Sheridan, A. (eds) Ancient Lives: Object, people and place in early Scotland. Leiden: Sidestone Press, 73-91.

Ellsworth, E. (2005) Places of Learning: Media, architecture, pedagogy. New York: RoutledgeFalmer.

Ellsworth, E. and Kruse, J. (eds) (2013) Making the Geologic Now: Responses to material conditions of contemporary life. Brooklyn, NY: Punctum Books.

Kuby, C.R., Rucker, T.G. and Kirchhofer, J.M. (2015) " "Go be a writer": Intra-activity with materials, time and space in literacy learning'. Journal of Early Childhood Literacy, 15 (3), 394-419.

Massey, D. (1994) Space, Place and Gender. Minneapolis: University of Minnesota Press. 
McArthur, A. and Kingsley Long, H. (1957) No Mean City. London: Corgi Books.

Ninth Lucknow International Children's Film Festival Brochure (2017).

Perry, M. and Medina, C. (2011) 'Embodiment and performance in pedagogy research: Investigating the possibility of the body in curriculum experience'. Journal of Curriculum Theorizing, 27 (3), 62-75.

Rosenstone, R.A. (1995) Visions of the Past: The challenge of film to our idea of history. Cambridge, MA: Harvard University Press.

Somerville, M. (2007) 'Place literacies'. Australian Journal of Language and Literacy, 30 (2), 149-64. 